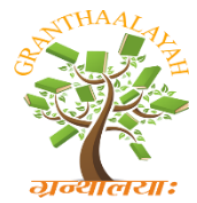

\author{
INTERNATIONAL JOURNAL OF RESEARCH \\ GRANTHAALAYAH \\ A knowledge Repository
}

Science

\title{
RESEARCH AND DEVELOPMENT OF ADDITIVE TECHNOLOGY IN INDUSTRIAL MANUFACTURING OF NEW PRODUCTS IN KAZAKHSTAN
}

\author{
Railya Mukhamadeyeva *1 \\ ${ }^{* 1}$ Kokshetau Abay Myrzakhmetov University, Republic of Kazakhstan
}

\begin{abstract}
The main goal of the project is to investigate the possible ways of introducing the additive technologies, to study the peculiarities of the layer wise synthesis process when producing foundry patterns and defining basic parameters which influence the quality of the produced parts. Based on the analysis of the results of activities aimed at the development of three-dimensional printing in Kazakhstan, highlighted the alleged problems of the successful implementation of additive technologies in the economy and in education particularly. In article the scheme of the existence and development of new technologies and the role of government's support in the process is given. The results of data analysis from the Internet shows that there is a sufficient number of threedimensional modeling laboratories, but it is mostly commercial service companies in the field of three-dimensional printing. The key factor in the growth of any economy is to organize an effective system of technology transfer and its further improvement.
\end{abstract}

Keywords: Additive Technology; Three-Dimensional Printing; Innovation in Technical Education.

Cite This Article: Railya Mukhamadeyeva. (2019). "RESEARCH AND DEVELOPMENT OF ADDITIVE TECHNOLOGY IN INDUSTRIAL MANUFACTURING OF NEW PRODUCTS IN KAZAKHSTAN." International Journal of Research - Granthaalayah, 7(2), 121-133. https://doi.org/10.29121/granthaalayah.v7.i2.2019.1014.

\section{Introduction}

Additive technologies (Additive Manufacturing, AM) - a term that is currently logged into use almost in all sectors and spheres of human activity. Heavy industry and dentistry, foundry and cooking, light industry and construction. Successfully conducting research in the field of 3Dprinting in tissue engineering to create artificial human organs.

The main goal of the research is the issue of considering the possibility of introduction of additive technologies in industrial production, the study of features in process of layered synthesis in the manufacture of prototypes and models and the definition of the main parameters affecting the quality of the produced parts. Scientific novelty and practical importance of the research of 
additive technologies to Kazakhstan's obvious. First of all, is the creation of a new area of technological knowledge for industrial production. In addition to the economic efficiency of the implementation of additive technologies in production, it has a high social value. Additive technology - a completely new technology for Kazakhstan, for which there are no books and methodical recommendations. ${ }^{1}$ The research results can be the basis for a new branch. This, in turn, will not only speed up the introduction of new technologies, but also to raise the level of preparation of graduates of technical specialties, and successfully adapt them to the world technological space.

Analysis of the situation regarding the implementation of additive technologies can be made on the base of 3D Print Conference, held in the territory of the CIS and Kazakhstan. Specifically, in the Republic of Kazakhstan held two events in Almaty, the events names were - advanced technology conference of three-dimensional printing and scanning - 3D Print Conference. They were held by the initiative of an international company - organizer of events Smile-Expo. ${ }^{2}$ First of all, it should be noted that all ongoing activities focused on businessmen and entrepreneurs in Kazakhstan. 3D printing and scanning- is recognized as one of the most promising technological directions.

\section{Scope}

The basic principle of the technological direction of additive technologies is a layering of material build-up. The concept of "rapid prototyping" or Rapid Prototyping (RP) was spread among industrialists and engineers. ${ }^{3}$ Today when searching for information you can use terms prototyping, three-dimensional printing, additive technologies, layered synthesis and others.

There is evidence that the prototyping technology has been known in the defense industry laboratories in the middle of the 20th century. After the destruction of the military-industrial complex in Germany and impossibility to support the patent the general idea and description of the process of creating layered parts become open and accessible to the masses. ${ }^{4}$

Curious facts about using three-dimensional pictures are known. In 1904 Carlo Bice received a patent for the invention process of producing plastic objects. He proposed to use a photosensitive gelatin, which expands in volume depends on the degree of exposure light.

Depending on the method of connecting the layers, methods of material coating, different variants of technologies can be identified. It should be noted that there is no a classic and well-defined classification of additive technology. Depending on the country and the manufacturer its own definition and separation of technologies can be given.

It is possible to identify the main technologies that are the base for a wide variety of currently existing methods of layer build-up. 
Table 1: The story of the three-dimensional printing

\begin{tabular}{|l|l|l|l|l|}
\hline Company & Country & Technology & Founded & $\begin{array}{c}\text { Date of release of the first } \\
\text { products on the market }\end{array}$ \\
\hline 3D Systems & USA & SLA & 1986 & 1988 \\
\hline EOS & Germany & SLS & 1989 & 1990 \\
\hline Stratasys & USA & FDM & 1989 & 1992 \\
\hline Z Corp & USA & MIT & 1991 & 1996 \\
\hline
\end{tabular}

(Compiled by the author according too ${ }^{5}$ )

The founder of 3D Systems in 1987 is Charles Hull, who patented SLA technology - Laser Stereolithography, in the literature sometimes the abbreviation SL can be found. Under the influence of computer-controlled radiation occurs hardening of photopolymer layer with thickness of a few hundredths of a millimeter, then the shelf for printing falls down and again covered with liquid. Then all repeats, as a result, ultraviolet ray "paints" a volume figure.

The company 3D Systems Corporation was initially focused on engineering, but in January 2012 was completed the process of acquisition of Z Corporation and Vidar Systems, that, in turn, has allowed the company to expand the application area of additive technologies. Decisions of $\mathrm{Z}$ Corporation covers the entire process of three-dimensional computer-aided design and building information modeling - BIM, and Vidar Systems Company specializing in equipment for medicine and dentistry. Thus, at present 3D Systems is a leading provider of printing three-dimensional content solutions: 3D-printers, consumables and services for the production of non-standard parts for a wide range of consumers. ${ }^{5}$

As for the company EOS GmbH - Electro Optical Systems, it appeared in 1989 and was founded by Hans Langer, as a pilot project for BMW. SLS method was invented by Charles Descartes in 1986. In additive technology direction is sintering of polymers, direct laser sintering of metal laser sintering and sand. Their interests have been in the manufacture of molds for injection molding and casting molds, prototypes and finished products for the automotive industry.

Stratasys was founded in 1989 by Scott Crump and his wife Lisa. The idea of technology came to Crump in 1988, when he decided to make a toy frog for his little daughter of wax candles using the glue gun, loaded with a mixture of polyethylene.

Stratasys Ltd is well known name in the market of innovative equipment, in early 2013, world leaders of rapid prototyping Stratasys company and Objet systems joined together and chose brand for a new company - Stratasys Ltd.

Thus, technologies that were the first:

SLA - hardening of the photopolymer resin by UV lamp or laser. Also it is called stereolithography, when under the influence of radiation managed by computer solidification occurs in the layer with thickness of a few hundredths of a millimeter, while the model shelf descends again and wetted. Each layer is drawn with a laser according to the laid down in the three-dimensional digital model. ${ }^{6}$ Laser irradiation leads to polymerization (i.e solidification) of the material at points of contact with the beam. Layer thickness for building parts is the magnitude on which shelf moves and may be 
from $0.05 \mathrm{~mm}$ up to $0.15 \mathrm{~mm}$. Ultraviolet ray forms volume shape. Such process is most prevalent among the other systems. The most significant disadvantage is the need to create support elements if the upper cross-sectional area greater than the lower parts. Support elements are temporary structures removed manually after the completion of the manufacturing process.

After construction is complete, the product is washed to remove residual material and, if required, material is processed in the ultraviolet furnace until hardening photopolymer.

The main advantage of stereolithography is a high precision ofprinting. This technology allows to apply layers with thickness of 15 microns, which is several times smaller than the thickness of a human hair. Precision of manufacturing is high enough to use in the manufacture of jewelry and dental prostheses prototypes. If considered the high resolution of such devices, print speed is rather high: the time of construction of the same model may be only a few hours, but eventually depends on the model size and the number of laser heads used by the device at the same time.

Relatively small desktop device may have an area of construction from 50 up to $150 \mathrm{~mm}$ in one dimension. At the same time, there are industrial equipment capable to print large models where the product size has already measured in meters. Finished products can have different mechanical properties depending on the inherent characteristics of the photopolymer: there are exist simulators of solid thermoplastics, rubbers and other materials.

SLS method technology essence is layered sintering of powder material by laser radiation. It is preheated in the working chamber, just before reaching the melting point. After leveling the powder on the surface of treatment area by CO2-laser, desired contour is sintered, then a new layer is poured, leveled, and the process repeats. Finished model is removed from the chamber and all excess powder is removed. Using a wide range of cheap and non-toxic materials (powdered polymers, casting wax, nylon, ceramics, metal powders), low deformations and tensions, the ability to make several models in one chamber simultaneously, all this provide SLS with relatively high ratings in the market of rapid prototyping systems.

SLS is often mistakenly confused with a similar process which called selective laser melting (SLM). The difference is that SLS provides only partial melting necessary for sintering the material, while the selective laser melting involves complete melting necessary for constructing monolithic models.

In comparison with other methods of additive manufacturing, the SLS has a high universality in the choice of consumables. These include various polymers (e.g., nylon or polystyrene), metals and alloys (steel, titanium, precious metals, cobalt-chrome alloys, etc.), and composites and sand mixtures.

The main advantage of SLS is that it does not require the construction of support structures. Suspended parts of the model are supported by unspent material. This approach allows to achieve almost unlimited geometrical complexity of the manufactured models. However, finished products have a rough and porous structure, and during changing the material the entire cleaning of chamber is required. 
The last of the patents for SLS technology was claimed in January 28, 1997. Its term expired in January 28, 2014, which makes this technology publicly available. ${ }^{7}$

FDM (Fused deposition modeling) - modeling method by layering fusing of sequential layers coating material, which repeats the contours of the digital model. Usually, thermoplastics supplied in the form of of rods or coils of strands serves as materials for printing. The plastic strand is fed into an extruder where it is heated and molten material is welded through the nozzle to the building model. As a rule, the upper part of the nozzle is cooled by a fan to create a temperature gradient required to ensure a smooth supply of material. Extruder head is moved in two coordinates, synthesizing a certain layer of the model. Then, the platform is lowered, the next layer is created, and so on. The product, or "model" formed by layers, which frozen immediately after extruding. As FDM advantages can be noted: ease of adjustment from one material to another, non-toxic, low cost and relatively high productivity, low temperature processing, and minimum operator intervention in the functioning of the equipment. Also the positive is the possibility of printing different colors of the same type of plastic to create a single model.

The main problem can be considered the need of support for creating overhanging surfaces. It is possible to print a model of a single material with printing towers from another of a readily soluble material that will allow you remove the support elements easily after finish of the printing process. Furthermore, when printing FDM some welds formed between layers, possible reason can be bundle of temperature fluctuations during the processing cycle, and thus the quality of the surfaces can not be high, if one layer capacity model is $0.25 \mathrm{~mm}$, so four-layer parts are placed on $1 \mathrm{~mm}$. If part has an angled wall, which is not perpendicular but inclined table, then stages will be visible on it every $0.25 \mathrm{~mm} .^{8}$

Among the used plastic materials ABS and PLA, polyphenyl, polycarbonate and polyetherimide. These materials are valued for their heat resistance. Some embodiments of polyetherimide, in particular, have a high fire resistance, which makes them suitable for use in the aerospace industry. FDM is the cheapest method of printing, it provides a high popularity. Currently, on this technology some russian printers is already created such as PICASO 3D Designer and Kazakh 3DLAB Prusa.

MIT Technology - (Massachusetts Institute of Technology) - layer by layer bonding of particles made from powdered materials with using a binder composition supplied through the ink-jet head. Difference of this method is the absence of need to press the supporting structures, called "legs" or "support" for stabilization hinged components of models. ${ }^{7}$

By force of gravity plastic string simply falls into the space without support, in the case of powder bonding, each layer serves as a natural support for the next layer. Worth noting economical technology: the residual powder can be collected from the working chamber when printing is complete, and use it in the further production cycle.

MIT technology is very popular and is used in wide variety of industries, often losing its original designation. Option known as "droplet / ink jet printing" or DOD (Drop on Demand) is used in the field of bio-printing technology. This method is used for layering live cells with the purpose of constructing the organic tissue. 
One of the best methods applying MIT was the creation of ChefJet confectionery printers, which builds three-dimensional models of the edible sugary foods, connecting particles with water, such as the original "plaster" printers.

On the basis of AM, after finishing the patent, a huge number different additive technologies appeared. All this technologies work by a principle of layered synthesis and its number grows every day.The most popular: Layer Object Manufacturing(LOM), color ink-jet printing (CJP), Solid Ground Curing (SGC), DLP, Poly-Jet and many others.

In general, we can talk about the division of additive technologies in inkjet and non ink-jet. This classification gives an idea of connection layers and allows you to immediately plan the quality of the model surface. ${ }^{9}$

In the case of inkjet technology either construction material or connection material can be supplied. In any case, the thickness of supplying material (strands diameter or adhesive volume) will affect on the quality of the surface because it determines the roughness parameter.

\section{Importance}

An important parameter in determining the quality of surface in three-dimensional printing is the quality of the original three-dimensional CAD-model. Known definition of the technology is production method or combination of methods, processes and materials for specific products. For the consumer when choosing product the main characteristic is its value and quality. The main advantage of the additive technologies is maximum realization of requirements and possibility of obtaining exclusive products at minimal expenses.

Exclusivity of products is created on the first step of new technology at design stage. You must accurately present the subject of production and have it digitized three-dimensional model.

Existence of three-dimensional electronic model is sine qua for additive technologies. Now you can be offered three options for obtaining CAD-model: from the Internet using existing databases; 3-D computer-aided design and 3-D scanning, as indicated in Figure 1.

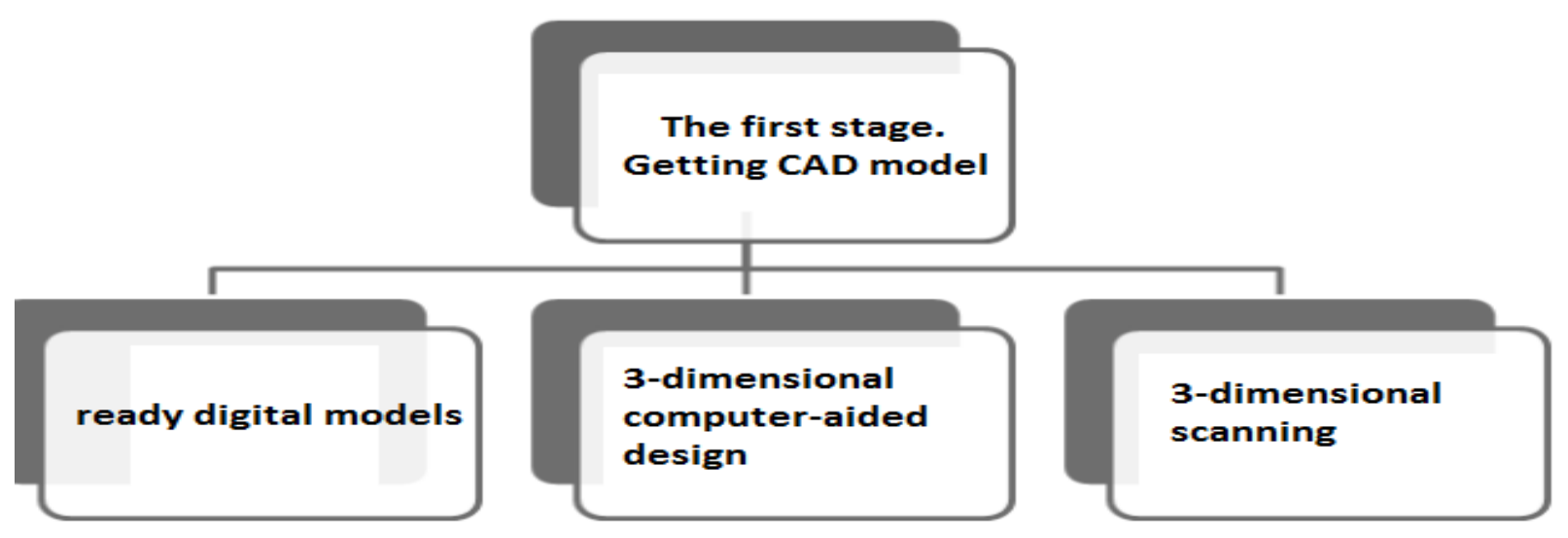

Picture 1: Production CAD-model (Compiled by the author according too ${ }^{5}$ ) 
Finished models can be available for free in the library of 3D-models, for example, at http://3d.masterkit.ru/shop/library, 3D Marvels, GrabC AD etc., or may be sold at specialized sites. For example, in the manufacture of jewelery the most time consuming procedure is to create a wax prototype. At this stage of the jewelry manufacturing technology spends the largest part of the total time of technical process. With appearance of 3D printers, jewelers getted the opportunity to grow quickly any wax jewelry models. For small-scale production is very popular library for jewelers at http://www.jewellerytech.ru/.

Already possible to find in the internet a lot of resources offering to download virtual prototypes of different subjects with different quality of execution. As in the case with traditional data stores of digital content (photos, music, videos), 3d-library is always updated and provide services for a fee or free of charge.

As a rule, there are no special requirements in free online directories of models. Users determine themselves the usefulness and quality of each model. At this time, the largest recommended base of models for $3 \mathrm{~d}$ printing is placed on the resource www.thingiverse.com, owned by the company MakerBot, also usefull for downloading http://www.quality3dmodels.net, http: //www.3dmodels .su, http://3dfind.ru. The most famous sites of paid models http://www.the3dstudio.com, http://www.templates.com/product/3d-models.

Three-dimensional computer-aided design is modeling in software programs that allows to convert into an acceptable format for three-dimensional printing.

For the post soviet space the most popular are AutoCAD, T-Flex CAD, Pro Engineer, Rhino software package, Maya, and the SolidWorks, which are ideal for 3D modeling.

Concerning products which may also be used to create three-dimensional models for printing, it should be mentioned:

Google SketchUp is free and is known for its ease of use. To build models in the SketchUp, you should draw contours and use the Push / Pull tool (push / extrude). Any flat surface can be transformed into a three-dimensional fashion shape. The program can work in conjunction with the Google Earth program from which you can upload a photo of the landscape (relief) areas, or build models in SketchUp, which can be seen in Google Earth. This program allows you to create three-dimensional shapes of varying complexity, but it focuses mainly on architects and interior designers.

3Dtin is the simplest program for 3D modeling. You can draw directly from the browser.

Blender is a free, accessible content of sets for 3D modeling, which are suitable for all major operating systems. Blender was developed for internal use by Dutch animation studio NeoGeo. Blender is focused primarily on animators and game developers.

OpenSCAD is software program for creating solid 3D CAD objects. It is enough accurate tool for creating three-dimensional parts of engineering. This program is free. 
Tinkercad is way to create models more quickly for printing on 3D printer. There are three main tools which provide a wide range of opportunities to create many useful things. As soon as project is completed, download the STL-file and start 3D printing.

The advantages of all these programs are cross-platform operating system, work in Windows operating system, as well as OS X, and in various Linux distributions. ${ }^{10}$

In general, there are many programs to design $3 \mathrm{~d}$ models, basically, they all work on the same principle and the differences between them are reduced to a set of functions and features in the interface. With the working skills with one of them, you can easily learn others.

As a guideline, manufacturers and users from different websites are advised to start with the program Blender, equipped with all basic tools and give complete overview of functioning 3D editors.

As for Kazakhstan, we can assume that the most widespread software package for creating threedimensional models is KOMPAS-3D, as indicated in Figure 2, company Ascon. ${ }^{11}$

ASCON - Russia's largest developer of engineering software and integrator in the field of automation of design and manufacturing activities. In company's products are implemented achievements of the Soviet school of mathematics, 26 years experience in creating CAD and perfect expertise of data in the design and management in engineering and construction. ASCON software used by more than 9,000 industrial enterprises and design organizations in Russia and abroad. 3D-print today is no longer innovation it turns into usual business and KOMPAS-3D becomes habitual tool for many users.

The main advantages of software are:

- Russian, very simple interface that gives you a clear advantage over foreign design systems, it contributes to the rapid training of working in the program, even who first sat down at the computer;

- Ease of use;

- The availability of teaching materials and methodological literature that is available and distributed free of charge;

- A two-level training (freeware version for non-commercial home computers and licensed version);

- Universality (for machine-building, instrument-making, construction and other fields.). 


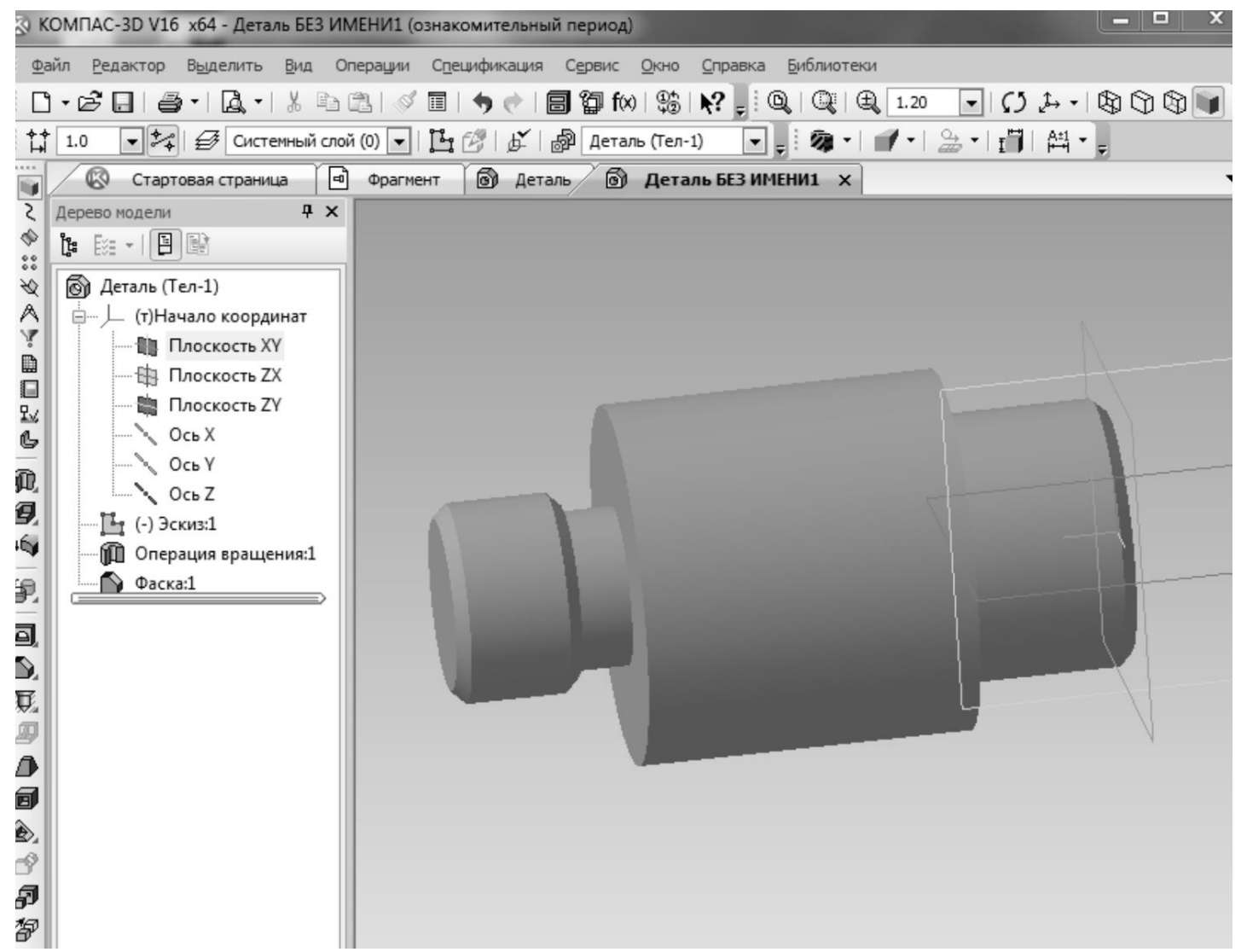

Picture 2: Shaft model, created in the program KOMPAS-3D (Compiled by the author according $\operatorname{too}^{11}$ )

Three-dimensional modeling system KOMPAS-3D is widespread in Kazakhstan through Ascon official dealers in Karaganda and Ust-Kamenogorsk and successfully used at the leading enterprises. Opportunity for universities to purchase KOMPAS licenses has allowed tens of educational institutions of Kazakhstan to open the program course in the educational process. Drawing schoolbook for grade 9 is approved by the Ministry of Education and Science, it contains a section about computer graphics in KOMPAS-3D system. Annual competitions and contests carried out by Ascon allow to determine the level of younger generation's interest in new possibilities of three-dimensional modeling. ${ }^{12}$

The third variant of receiving digital model is a three-dimensional scanning. Absolutely similar to the two-dimensional printing, when it is too difficult and time consuming to type already existing text, it can be scanned. Special equipment is used to scan a real object, especially, a threedimensional scanner.

Operating principle of three-dimensional scanner is based on stereo vision. Just as a person with two eyes is able to determine distance to objects so $3 \mathrm{~d}$ optical scanner calculates the coordinates of points using two cameras and a computer for processing final images. In addition to cameras additional illumination is used, it helps to achieve high accuracy and reliability. 
After the process of $3 \mathrm{~d}$ scanning all necessary information about structure and shape of the object, it is used by computer that already occurs data analysis and the construction of an accurate computer model of the object.

\section{Review Process}

Nowadays, when profits of enterprises depends on the speed of response to market needs, necessary using of new technologies that provides updating its range of products in short terms. For successful business development you need to respond quickly to growing and changing demands of consumers, this means greatly simplify, accelerate and reduce expenses of manufacture. ${ }^{13}$

From the above it can be concluded that using of computer solid modeling provides a rapid expansion of additive technology and a its market price will be decreased. The cost of printed product will depend on uniqueness and quality of three- dimensional digital model much more than on material and equipment. All of this suggests that technologies and systems of $3 \mathrm{~d}$ printing will occupy an increasingly large place in our lives.

Analysis of the situation below regarding the implementation of additive technologies has shown that as weaknesses for development new technologies in Kazakhstan may be key factors:

- absence of clear understanding of equipment purpose of and its inefficient use;

- unprofessional service;

- Lack of technical support. No quality advice due to the lack of highly qualified specialists.

The main threats to transfer new technology in Kazakhstan is human potential. As professional will be experts who will make adaptation of new technology in the country, and so will be the level and terms of development and introduction of additive technologies.

In Kazakhstan Technopark "Algorithm" in the city of Uralsk purchased Stratasys company equipment in 2007, which was immediately rented by industrial enterprise JSC "West Kazakhstan Engineering Company". In 2009 at Karaganda technopark appears VoxelJetmachine. Innovative technology are used to create new products at the machine building enterprises of the republic.Also new technology came in educational process. At present more than a dozen educational institutions of Kazakhstan have a three-dimensional printers. ${ }^{14}$

The situation is changing every year and has a positive trend. In 2014 and 2015 there were two events in city Almaty, events were called - conference of advanced technology and threedimensional printing and scanning - 3D Print Conference. They were held at the initiative of the international company - organizer of the event Smile-Expo. ${ }^{15}$

First of all, it should be noted that all the activities carried out were aimed at businessmen and entrepreneurs of Kazakhstan. 3D-press scan and are recognized as one of the most promising technological directions. 
According to results of analysis these activities in the Republic of Kazakhstan, we can say that existing information about additive technologies represents by a number of controversial proposals without adequate scientific and engineering work.

Complexity of the process, absence of a mathematical model, which would enable to calculate characteristics of three-dimensional printing with needed accuracy, such as shrinkage, deformation, force, contact pressure, etc. It allows us to speak about insufficient degree of researches into new technologies, as indicated in Figure 3.



Figure 3: The Basics of existence and development of new technologies (Compiled by the author according too ${ }^{14}$ )

Additive technologies have great potential in reducing energy expenses for creation wide variety of products. Level of using AM-technologies in production of goods is a faithful indicator of real industrial situation it is indicator of its innovative development. ${ }^{16}$

\section{Review Process}

At the moment there is an active implementation in all areas of new equipment, working on additive technologies. This technology, based on a constant build of three-dimensional digital model obtained by modeling or scanning. With the necessity to move Kazakhstan economy from raw materials to service and technology, highly relevant is an implementation of computer aided design systems and development of techniques to create three-dimensional models into the educational process. CAD systems and speed up of production, including development work will be required to assist the creation of the technology-intensive industrial sector in the Republic. Correspondence with international standards in the industry and in education will create the conditions for successful entry of Kazakhstan into the world market and its participation in the international division of labor.

The result was the release of the main tasks for the near future on the development of additive technology in the Kazakhstan:

- organization of working group on the creation of the design industry, the definition of the main participants, sources of financing, range of consumers of developed products;

- create a new model of introduction of perspective technologies in the additive industry by organizing a consortium of different sectors of the industry, as part of which can be 
represented as manufacturers and consumers of technological solutions, including large companies with state participation;

- The establishment within the Foundation of perspective researches (FPR) for the organization of the laboratory breakthrough research;

- Creation of a unified coordination mechanism - a single center of competence on additive technologies;

- preparations for the new academic year, proposals on development of the system through the training of specialists in the field bases of intellectual and information technology, computer simulation, robotics and additive technologies;

- Creation of a system of national standards for additive manufacturing, including:

- general and special qualification of materials (source and synthetic);

- standardization of designs, technologies and equipment;

- The development and certification of quality control methods and properties of synthesized materials and products;

- rules of applying additive manufacturing products (assessment of safety, forecasting term).

- Thus, in accordance with the scheme composed for implementation of additive technologies are necessary:

- Fundamental knowledge based on scientific principles;

- Specialists teachers to transfer skills;

- Equipped workshops and laboratories for the acquisition of skills;

- A new specialty in high school.

And most importantly, based on the above we can suggest that the successful development of new technologies requires the support of the state. ${ }^{17}$

The possibility of qualitative development and implementation in production, and most importantly in the educational process of new additive technologies will help to boost industrialinnovative development of Kazakhstan, and will enable young professionals feel more confident in the international market. ${ }^{17}$

\section{References}

[1] Muhamadeyeva R. M. "Technology transfer is prototyping in Kazakhstan", Germany, European Applied Sciences, №5, 2013 pp.15-17

[2] Muhamadeyeva R.M. The parameters of additive technology in 3D printing, the Eurasian Union of Scientists (EUS). 2014, IV:118-119

[3] Zlenko M. A. "Additive technologies in mechanical engineering" /MV Nagaitsev, VM Dovbish // manual for engineers. - M. GNC RF FGUP "NAMI" 2015. 220 p.

[4] Kozemchuk K. Dovbish B. Additive technologies in Russian industry. Scientific and technical statements of St. Petersburg State Polytechnic University. 2013, 4, S. 183

[5] Muhamadeeva R. M., Nazarenko M., Okselenko O., Abayeva N. F., Golovachyova V. N., Baidak Y. "Innovations in technical and natural science". Monograph, Volume 2/ ed. by P. Busch. Vienna: "East West" Association for Advanced Studies and Higher Education GmbH, 2016. - 56 p.

[6] Grigoryants A. G., Novichenko D. Y., Smurov I.Y. "Laser additive manufacturing techniques and coatings of parts made of composite material" Proceedings of the universities ,2011, №7, pp.38-46

[7] http://3dtoday.ru/wiki/3D_print_technology/ (date accessed: 07/22/2014) 
[8] Muhamadeyeva R. M. "Parameters of additive technology at the 3D printing", The International scientific and practical "Europe-Asia" conference, 4, 2014, p.118

[9] V.S. Doroshenko "3D-technology in metal casting ITB" Casting of Ukraine, №03 (151) 2013 pp. $16-18$

[10] Muhamadeyeva R. M. "Methodological Guide Drawing". Textbook for Grade 9. Kokshetau, Publisher "Keleshek". 2013

[11] Muhamadeyeva R. M. "Computer aided design system in the education procces of competitive professionals" "Global Science and Innovation" Materials of the V international scientific conference, s. 353-355. Chicago, USA 2015

[12] Muhamadeyeva R. M., Muhamadeyeva. A., Akoxova N. V. "Problems of technical and vocational education in Kazakhstan". Scientific publications Journal "Actual problems of the humanities and natural sciences» №11, part VI of, Moscow, 2015. pp 108-112

[13] Techel A. et al., "Laser Additive Manufacturing of Turbine Components", Precisely and Repeatable. Fraunhofer Institute for Material and Beam Technology (IWS), [Electronic resource is] the regime of the access.: http://www.lia.org/blog/category/laser-insights-2/laser-additivemanufacturing/

[14] Muhamadeeva R. M. "Implementation issues of additive technologies" International journal of engineering sciences \& research technology № 5(2): February, 2016

[15] Materials 3D Print Conference, news@3dprintconf.com.ua

[16] 3-D Printing Manufacturing Process is Here.; Independent global forum for the Unmanned Aircraft Systems community, UAS Vision. [Electronic resource is] the regime of the access: http://www.uasvision.com/12/07/16/3-d-printing-manufacturing-process-is-here/

[17] Muhamadeyeva R. M., Muhamadeyeva T. M., Muhamadeyeva I. A. "Structural and Logical Approach to the Introduction of Dual Training in Vocational and Technical Education System of the Republic of Kazakhstan" Indian Journal of Science and Technology, Vol 8(S10), December 2015

\footnotetext{
*Corresponding author.

E-mail address: raulia@ list.ru
} 